\title{
LA INTERNACIONALIZACIÓN DE LA INDUSTRIA DE LA EDUCACIÓN: EL CASO AUSTRALIANO
}

\section{Introducción}

\section{Contexto de los objetivos de la reflexión}

Hace trece años, Sheila Slaughter y Larry Leslie publicaron un libro -Academic Capitalism: Politics, Policies and the Entrepreneurial University (1997) - que se convirtió en referencia entre aquellos que analizan la educación superior. Para los autores, el capitalismo académico resulta de la explotación intensiva del capital humano formado por académicos vinculados a las universidades, con potencial de fomentar conocimiento, capaz de atraer intereses de representantes del sector productivo. Con la gestión académica orientada a este objetivo, la responsabilidad social de la universidad se reduce a su capacidad de producir conocimiento económicamente útil. De esta forma, ella pasa a competir en la comercialización de productos y servicios derivados de la producción de conocimiento y de esta forma ampliar las condiciones que favorezcan la diversificación de sus fuentes de recursos financieros ${ }^{3}$. ¿Por qué después de la década de los ochenta las universidades tendrían necesidad de diversificar sus fuentes de recursos financieros? ¿Cuál es la participación del Estado en el proceso de transformación de las instituciones universitarias en organizaciones?

Con el fortalecimiento de la competencia global creció la importancia de la ciencia y tecnología (CyT) y de la formación de cuadros calificados. Comprensivamente, las inversiones en proyectos de investigación y educación pasan a ser reconocidas como estratégicas;

3 Explotación de actividades relativas a programas de enseñanza y de capacitación, presencial y no presencial, en el ámbito nacional e internacional, educación continua; enseñanza de lenguas; exámenes y certificaciones, producción de C\&T/P\&D; difusión del conocimiento por la edición y distribución de revistas, libros, software y videoconferencia; aplicación del conocimiento por medio de registro de patentes, oferta de consultoría, formación y mantención de incubadoras de empresas y parques industriales serían ejemplos de lo que las autoras desean enfatizar. 
tanto en el ámbito de los individuos como de las organizaciones, estados y regiones "los intereses económicos ligados a la enseñanza superior son estratégicos para los estados ricos y para las empresas en el contexto de la economía basada en el conocimiento y en la competencia", refuerzan Brouillete y Fortin (2004, p. 9). Los números que reflejan el incremento de la educación superior son impresionantes: mientras en 1970 el universo de estudiantes correspondía a 28.6 millones, en 2007 la población estudiantil llegó a 152.5 millones, con un crecimiento medio anual correspondiente a 4,6\% (UNESCO, 2009, p. 10).

Ante esto, el Estado se revela incapaz de hacer frente solo al volumen de inversión requerida por los programas de educación y fomento a la investigación. Frente a la necesidad de ser competitivo y de que las universidades preserven el prestigio conquistado, éste adopta políticas con menos reglamentos en el sector educacional para favorecer su explotación comercial. Mientras entre los países periféricos y semiperiféricos tales medidas tuvieron importancia en la privatización de la educación superior; entre los países del centro esto representó una forma apropiada de privatización. Las universidades públicas y privadas explotaron intensivamente la capacidad de trabajo de profesores e investigadores, ampliaron la cartera de servicios educacionales, conquistaron nuevos mercados y diversificaron las fuentes de recursos financieros para el autofinanciamiento, tanto de las actividades de enseñanza como de investigación y extensión ${ }^{4}$.

Con la adopción de políticas de inspiración neoliberal, la función social del Estado es repensada, la desregulación de los servicios esenciales (aprovisionamiento de agua, electricidad y sanidad básica; inversión en programas de salud pública, transporte, vivienda, educación, investigación, cultura, entre otros.) es formalmente reivindicada ${ }^{5}$, y los programas de privatización son ampliados.

4 Es revelador que al escribir un artículo cuyo contenido profundiza en aspectos relativos a la política de financiamiento de la educación superior en Australia, Grant Harman -profesor de la Universidad de Nueva Inglaterra (Australia) - se refiera al estudiante como cliente (ver p. 12). En el mismo texto, el autor declara "on tente notamment de lutter contre le manque de fods en recrutant des étudiants étrangers et en lancant des activités comerciales" (p. 20).

5 Ilustrando con el caso de la educación, cuatro países reivindicaron formalmente la liberalización del comercio mundial de servicios derivados del área educacional en el World Trade Organization: EUA (protocolos/CSS/W/23, en 18/12/2000), Nueva Zelanda (protocolo S/CSSW/110, en 1/102001); Japón (protocolo S/CSS/W/137, en 15/03/2002). 
Así, las políticas neoliberales han implicado en la "promoción de mecanismos de mercado en el interior del espacio estructural del Estado, liberalizando y promoviendo presiones competitivas entre servicios, transformando los usuarios en clientes, privatizando, adoptando instrumentos y principios de gestión basados en la racionalidad instrumental y subordinando los derechos sociales a la lógica de la eficacia y eficiencia" (Afonso, 2003, p. 39). De esta forma, la subsistencia del sistema de educación superior depende cada vez menos de inversiones del Estado y cada vez más de la competitividad alcanzada por las organizaciones universitarias con la comercialización de productos y servicios, en escala mundial.

¿Por qué, desde la década del 90 en adelante, gran parte de la literatura se aproxima a la educación superior a través de un prisma internacional, en que las dimensiones culturales y políticas están subordinadas a la dimensión económica? Los países desarrollados presentan sistemas de educación superior consolidados, tanto en términos cuantitativos (número de instituciones, programas y matrícula) como cualitativos (calidad del cuerpo docente, de enseñanza e investigación). Por lo tanto, aun cuando son países con baja tasa de natalidad, la evolución del sistema educacional amplió la matrícula de tal modo que alcanzó la etapa de posmasificación (de casi universalización), en consecuencia, en estas regiones, el número de matrículas es decreciente (UNESCO, 2009). Luego, la sobrevivencia de las universidades (programas, cuerpo docente, grupos y programas de investigación, laboratorios, entre otros) depende de la "caza de estudiantes que financien sus estudios" (Charle et al. 2004, p. 968) ${ }^{6}$.

6 Una vez más el caso australiano es revelador de lo que se afirmó "compte tenu de l'expansion rapide des effectifs et du fait que l'enseignement postscolaire se repproche de la participation universelle, les sociétés e 'comme l'Australie éprouvent des difficultés a maintenir les niveaux de financement accodés par l'Etat, en particulier a un moment ou la demande de ressources publiques émanant d'autres secteurs de la société augmente et ou la volonté publique d'accröite les niveaux d'imposition fait souvent défaut. Cette situation incite les pouvoirs publiques et les etablissements d'enseignement post-scolaire a envisager de nouvelles solutions possibles en matiére de financement, notamment un recours croissant aux mécanismes du marché afin d'ameliorerléfficience et ládaptabilité, une plus large d'réglementation des controles en particulier suer les doits de scolarité, l'élargissement du role do financement e du secteur privé, et l'intensification des activités commerciales das les établissements d'enseignement supérieur eux-memes" (Harman, 1999, p. 20). 
La adopción de esta política desencadena diversas consecuencias: a) genera crisis en el interior de las universidades; b) compromete la función social de la institución; c) dificulta la democratización del acceso a la educación superior; d) genera la desvalorización y el debilitamiento de los sistemas de los países semiperiféricos y periféricos; e) amplía la distancia social, económica y política entre Norte y Sur; f) promueve la transferencia líquida de divisas del Sur para el Norte; g) favorece políticas deliberadas de fuga de cerebros; h) radicaliza la estructura dual de los sistemas de educación superior, entre otros (Afonso, 2003; Brouillette, Fortin, 2004; Cortesao, Stoer, 2001. Dale, 2004; Dias, 2002, 2003; Stoer, 2001; Santos 2001; Teodoro, 2001; Seixas, 2001, etc.).

La emergencia de una estructura dual en la educación superior resulta de la ampliación de poder académico y financiero de las universidades de investigación y del cuestionamiento de la legitimidad de las universidades de enseñanza. Así, a medida que las universidades de investigación, los centros de investigación y posgrado stricto sensu tienen potencial para identificar y responder a las necesidades del sector productivo, colaboran para elevar los niveles de eficiencia y competitividad en el ámbito de los mercados globales (Coggiola, 2001) y diversificar sus fuentes de recursos; las instituciones dedicadas a la enseñanza dependen solamente del valor de los aranceles pagados por alumnos-clientes. De esto modo, tanto las actividades de enseñanza como de investigación tienden a someterse a los intereses de la economía y del mercado. Con esto, las decisiones académicas son cada vez más dependientes de motivaciones económicas y cada vez menos comprometidas con las necesidades sociales. En consecuencia, las universidades como instituciones de la sociedad ceden lugar a formatos de organizaciones de mercado (Chauí, 2002; Santos, 2005, 1997).

¿Hasta qué punto sería posible asegurar que el proceso de transformación en curso en el ámbito mundial alcance el sistema de educación superior con la misma intensidad? Al investigar el impacto de la globalización sobre la enseñanza es posible observar que los sistemas nacionales de educación terciaria desarrollaron diferentes mecanismos de resistencia y esto generó lo que Boaventura de Sousa Santos (2001, p. 91) llama "globalización de baja intensidad". 
Para el autor, mientras la globalización de alta intensidad refleja procesos rápidos, intensos y relativamente monocausales, la globalización de baja intensidad produce procesos más lentos, difusos y ambiguos en su causalidad. ¿Por qué el impacto de la globalización sobre la organización del sistema de educación superior en Chile, México, Túnez, Nueva Zelanda, Australia, por un lado, y Alemania, Dinamarca, Finlandia, Suecia, Francia, por otro, es diferente? Mientras en el primer grupo de países los intercambios son desiguales, las diferencias de poder son grandes y la capacidad de negociación es reducida; en el segundo grupo prevalecen intercambios menos desiguales, o sea, las diferencias de poder entre países, actores y prácticas, por detrás de concepciones alternativas de globalización, son pequeñas. Esto equivale a asegurar que cuanto más fuerte el sistema político, mayor será su capacidad de manipular el sistema mundial a su favor (Santos, 2001, p. 99).

La comprensión de los conceptos de globalización de alta y baja intensidad depende del conocimiento de algunas contribuciones del sociólogo Immanuel Wallerstein. Al reflexionar más profundamente acerca del concepto de economía-mundo (weltwirtschaft: welt = mundo y wirtschaft = economía), acuñado por Fernand Braudel, el autor parte de la premisa de que el capitalismo depende de la preexistencia de un mercado mundial, ¿̇por qué? Tomando en cuenta que los productos (no necesariamente para el uso), el desarrollo de intercambios con el exterior y la existencia de un mercado mundial son condiciones inherentes a la emergencia y al desarrollo del modo de producción capitalista. Dicho mercado está asentado en varios estados nacionales y éstos, a su vez, se empeñan en influir en el funcionamiento del mercado global, de acuerdo con intereses de clases y grupos sociales. Así, "mientras más fuerte sea la maquinaria estatal, mayor será su capacidad de influir en el funcionamiento del mercado, en una escala geográfica significativa, que puede extrapolar los límites de su territorio" (Becker y Egler, 1993, p. 27).

En esta perspectiva, el Estado corresponde al instrumento político-económico, explotado por clases y sectores dominantes (regionales-nacionales), con la intención de tener parcelas del mercado mundial bajo su control. Para Wallerstein (1976), la compleja red de 
relaciones formada en el contexto de la economía-mundo no se agota en la división que envuelve las ideas de centro y periferia porque su permanencia depende de los estados semiperiféricos. Es en esta dirección que el autor clasifica las regiones del globo en tres niveles jerárquicos: estados centrales, semiperiféricos y periféricos. Los estados centrales poseen maquinarias políticas fuertes, abrigan el gran capital transnacional, disponen de tecnología de punta, son reconocidos por el poder de innovación -más radical que incremental (Nicolau, Paranhos, 2006)-, por las formas posburocráticas de organización, para llegar a la hiperflexibilidad, por medio de las relaciones en tiempo real. Ellos presentan densidad poblacional elevada, una fuerte cultura nacional; dominan las relaciones internacionales y por esto mismo definen políticas centralizadoras de capital y fijadoras de statu quo, a medida que crean mecanismos de legitimación de la apropiación de excedentes generados en la periferia. Gran parte de sus universidades está inserta en la lógica del capitalismo académico (Slaughter y Leslie, 2001, 1997), forma el analista simbólico (Reich, 1993) y desarrolla competencias típicas del intelectual cosmopolita (Ianni, 2005). Países clasificados de estados centrales alimentan el sentimiento de éxito justificado por los elevados salarios y por la capacidad de consumo de un importante contingente de la población, comparativamente con los países semiperiféricos y periféricos.

Los estados semiperiféricos, a su vez, asumen un papel fundamental en el funcionamiento de la economía-mundo, tanto en el plano económico como en el político. A pesar de presentar pocos sectores económicos verdaderamente dinámicos son simultáneamente explotados y explotadores. Con esto ellos reducen la oposición directa entre estados centrales y periféricos, y favorecen la estabilidad del sistema mundial ${ }^{7}$. En las regiones semiperiféricas, el Estado es instrumento indispensable del proceso de acumulación porque actúa como motor del crecimiento económico y de la actividad productiva. $\mathrm{Al}$ asumir el papel de financista -responsabilidad típica de los bancos

7 "La existencia de la tercera categoría (estado semiperiférico) significa precisamente que el estrato superior no enfrenta la oposición unificada de todos los otros porque el estrato intermediario es tanto explotado como explotador. Es por esto que el papel específicamente económico no es tan importante, y ha cambiado a lo largo de las diversas etapas históricas del sistema mundial moderno" (Wallerstein citado en Becker; Egler, 1993 p. 28). 
de inversión-, el Estado se vuelve deudor y las crisis económicas fácilmente se transforman en crisis políticas. Gran parte de los excedentes generados en la semiperiferia es fruto de la productividad de empresas con sede en regiones centrales, factor que hace inviable la acumulación de parte de la riqueza de los demás países en su territorio. Prevalecen la producción en masa y el trabajo precario de las fábricas tayloristas-fordistas, condiciones de existencia de las empresas de clase mundial. Predomina la enseñanza masiva, carente de sentido para jóvenes que poco aprenden, desprovistos del derecho de tener proyectos justificadores de la inversión en educación (Costa, 2004). Aquí, las instituciones de enseñanza asumen la nada gloriosa tarea de formar profesionales para un mundo sin empleo (Pochmann, 2005).

Finalmente, los estados periféricos aglutinan regiones de población más dispersa en que prevalece la explotación de productos derivados del sector primario; no hay formación de burguesía comercial y financiera ya que gran parte de los excedentes generados es enviada a las regiones centrales, las actividades productivas son intensivas en mano de obra y no en capital técnico, como ocurre en el centro. Son regiones formadas por excluidos, sin derechos, por no tener capacidad de consumo; controlados por aparatos de coerción y represión sociales para que no coloquen en riesgo la seudoestabilidad del mundo global.

Australia es clasificado como un país semiperiférico, grande en superficie y pequeño en densidad poblacional. Presenta un Producto Interno Bruto pequeño (comparado con el PIB de la mayoría de los países de la Organización para la Cooperación y Desarrollo Económicos, OCDE) y una pequeña participación en el comercio mundial. Desde fines de la década de los ochenta el gobierno local eligió la educación superior como principal producto de exportación y las cifras publicadas no dejan duda sobre el éxito comercial de la iniciativa. Con el soporte de la perspectiva teórica antes indicada, se pretende desarrollar reflexiones orientadas a responder la siguiente pregunta: ¿hasta qué punto es posible asegurar que la educación superior australiana es expresión viva del capitalismo académico? De ser efectivo, ¿qué tipo de consecuencia representa esto para el sector educacional superior? 


\section{Recursos metodológicos explotados}

Este ensayo es el resultado de la investigación documental y bibliográfica. La consistencia de esta última se debe al hecho de que la educación superior australiana suscita abundante publicación de trabajos académicos. Ante al fácil acceso al material, se decidió explorar dos categorías de textos: a) aquellos de autoría de profesores australianos vinculados a universidades tradicionales del país (con eso se pretende aprehender el sistema de educación "por dentro", en la perspectiva de los actores que viven la dinámica de funcionamiento de las instituciones, en la condición de profesores, investigadores y directivos); y b) textos de autoría de profesores de diversas nacionalidades, vinculados a universidades de reputación mundial, reconocidos por la contribución teórica en el área.

La consistencia de la investigación documental se debe a dos factores: en el ámbito nacional, al acceso a resultados de levantamientos realizados por la oficina especializada en la divulgación del sistema de educación superior australiano y en la captación de estudiantes extranjeros (International Development Programme Education Australia), además de diversos sitios web ${ }^{8}$; y en ámbito mundial, al acceso a resultados de investigaciones conducidas por organismos multilaterales o con su cancillería. La literatura sobre la internacionalización de la educación está dividida entre autores apologéticos, que reconocen las ventajas de encarar como negocio la educación superior, y autores críticos que entienden los programas de internacionalización desde una perspectiva más cultural y política que económica. La perspectiva interpretativa adoptada en este artículo se inscribe en esta segunda categoría.

8 http://wwwidpedu.au/index.htm; http://aei.detya.gov.au (sistema de educación postsecundario, valores a ser pagados por los estudiantes extranjeros; http://aei.detya.gov. au/students/education/aqf.htm (descripción de los diplomas universitarios; http://www. detya.gov.au/highered/research/aiprss.htm); http://www.otfe.vic.gov.au/provider/accredit/ aqf.htm de (equivalencia diplomas); http//aei.detya.gov.au/studants/costs/accommodation. htm (informaciones sobre alojamiento). http://aei.detya.gov.au/student/costs/budgeting.htm (previsión financiera para estudiantes extranjeros puedan sobrevivir durante el sejour); http://aei.detya.gov.au/students/living/default.htm (organización estudiantil de apoyo a estudiantes extranjeros). 


\section{Contextualización histórica y problematización}

La colonización inglesa se estableció en Australia durante 113 años (1788-1901) y comprensiblemente dejó marcas importantes en la organización social, cultural, política, y económica del país (Rossato, 1998, p. 163). Australia es la isla más grande del mundo y el sexto país en superficie, mientras su población, formada por 21 millones de habitantes, representa el 0,3\% de la población mundial, o sea, un contingente ligeramente superior a la población de la gran ciudad de São Paulo. La economía del país representa el 1,9\% del PIB de la OCDE y es responsable por, aproximadamente, el 1\% del comercio mundial (McBurnie, 2001), semejante a la participación de Brasil.

Hasta la década de los ochenta la economía australiana alcanzó resultados muy positivos en virtud de la capacidad de exportación de productos derivados del sector primario -en esa época el país dependía esencialmente de la extracción minera y de la agropecuaria-. Con la adopción de esta política comercial volcada hacia la exportación, los gobernantes consiguieron proteger el sector industrial, mantener una política de elevados salarios, además de preservar tasas de empleo internas favorables. ¿De qué modo la inestabilidad del ambiente internacional en las últimas décadas expuso las fragilidades de la economía del país? Tomando en cuenta que el éxito dependía de los precios atribuidos a los productos derivados del sector primario por el mercado internacional, a medida que tales precios sufrían fuertes oscilaciones, la economía australiana revelaba ser bastante vulnerable (Coaldrake, 1999; McBurnie, 2001). Es en este contexto que el gobierno del país estimó que la prosperidad nacional dependía de la ampliación de la competitividad que, a su vez, estaba sujeta a la adopción de dos medidas de corte neoliberal: la reducción del papel social del Estado y la ampliación de condiciones que favorecen la libre competencia. Movidos por tal convicción, los gobernantes definieron políticas de desregulación cuya implementación incidió en la reducción de gastos ${ }^{9}$ y en el desencadenamiento de transformaciones en diversos sectores de la

9 Entre 1987 y 1996 los gastos públicos fueron reducidos en torno a un 8\%; entre diciembre de 1996 y junio de 1999 la reducción alcanzó un 25\%, y las proyecciones para los 4 años siguientes estimaban una reducción próxima a los 22.8\% (Coaldrake, 1999, p. 134). 
economía, además de notorias modificaciones en el perfil del mercado de trabajo. El efecto adverso es que con la desregulación "Australia conoce un índice de desempleo invariablemente elevado y lo que es paradojal e inquietante: aquellos que tienen un empleo deben atender a las crecientes exigencias y frecuentes cambios de trabajo" (Coaldrake, 1999, p. 133) ${ }^{10}$.

La comprensión de la realidad por el prisma descrito también contribuyó para que los sucesivos gobiernos instituyeran políticas y definieran planes de acción capaces de alterar la base de la economía australiana de modo que la industria del conocimiento prevaleciera sobre los productos primarios, con fuerte presencia del sector terciario (McBurnie, 2001).

Frente a este cuadro resta saber en qué medida el sistema de educación superior vigente tendría condiciones de responder a tamaño desafío. ¿De dónde el gobierno extraería los recursos financieros y humanos que este cambio de ruta implicaría? ¿Cómo el país ha conseguido moldear la industria de la educación, transformar las universidades en empresas con diferentes unidades de negocio y la enseñanza superior en un producto de exportación atractivo y rentable? ¿Cuál es el grado de resistencia de las universidades? Al final, constituir el sistema de educación superior en motor del desarrollo socioeconómico del país presupone esfuerzos incalculables, particularmente cuando se toma en cuenta que hasta aquella fecha el 95\% de los recursos que hacían viable la educación superior del país provenían del gobierno federal (Fiemeyer, 2004, p. 60).

\section{El sistema de educación superior australiano}

La formación del sistema de educación superior australiano fue fuertemente influenciada por los modelos inglés y americano

10 "L'Australie connaît un chômage invariablement élevé et, ce qui est paradoxal et inquiétant, ceux qui ont un emploi doivent faire face à des exigences de plus en plus grandes et à une charge de travail de plus en plus lurde" (Coaldrake, 1999, p.133). 
(Coaldrake $^{11}$, 1999; Rossato, 1998; Charle, Verger, 1996) ${ }^{12}$. Incluso en el periodo colonial son fundadas las primeras universidades en importantes centros urbanos: Sydney (1850), Melbourne (1853) Adelaide (1874) y Tasmania (1890) (Dobson 2001, p. 9). Tomando en cuenta la población del país, el sistema de enseñanza terciaria no es pequeño, está formado por 39 establecimientos, de los cuales 37 son públicos y dos privados. Mientras las universidades públicas reciben algún aporte financiero del Estado, las universidades privadas son totalmente autofinanciadas con la comercialización de productos y servicios de carácter educacional (Meek, 2004).

Es posible clasificar los 37 establecimientos públicos en cinco categorías (Coaldrake, 1999, p. 150) y la taxonomía propuesta reproduce lo que Coggiola (2001) llama sistema dual de educación superior. El sistema australiano está formado por establecimientos dedicados a la investigación fundamental y aplicada (reconocidos por adoptar un riguroso proceso selectivo, atraer la elite académica y socioeconómica, y exigir de los estudiantes, profesores y gestores dedicación total) y de establecimientos exclusivamente dedicados a la enseñanza masiva (poco rigurosos en la selección de alumnos, volcados a las actividades de enseñanza, orientados para y por la formación profesional que, en la práctica, requiere dedicación en tiempo parcial, tanto de docentes como de estudiantes) (Brouillette, Fortin, 2004) (tabla 1).

11 Mientras para Coaldrake (1999, p.149), «le systéme universitaire australien a été crée a partir d'un amalgame de modeles, inspiré a fois des anciennes universités du Royaume Uni et des etablissements plus recents axes sur l'experience pratique a la fois au Royaume Uni et aux Etat Unis.», para Harman $(2002$, p.62) « traditionnellment, les universités australiennes se conformaient largement o modele de gestion et d'administration britannique... »

12 A final de 1980, el gobierno implanta programa de reformas en el sistema de educación superior, llamada Dawkins. El referido programa contenía alteraciones estructurales en la medida en que decidió por el cierre del sistema binario (coexistencia de universidades y colegios superiores), por la unificación del sistema nacional de educación superior y por la implantación de políticas educacionales que forzaron las instituciones a ajustarse a las necesidades económicas del país (Coaldrake, 1999, p. 134). 
Tabla 1: Taxonomía del sistema público de educación superior australiano.

\begin{tabular}{|l|l|l|}
\hline N. ${ }^{\circ}$ de establecimientos & $\begin{array}{l}\text { Caracterización de los } \\
\text { establecimientos }\end{array}$ & $\begin{array}{l}\text { Perfil de la población } \\
\text { estudiantil }\end{array}$ \\
\hline $\begin{array}{l}\text { 5 Establecimientos } \\
\text { regionales }\end{array}$ & $\begin{array}{l}\text { Especializados en programas de } \\
\text { formación a distancia (enseñanza). }\end{array}$ & $\begin{array}{l}\text { Atraen pocos estudiantes } \\
\text { extranjeros }\end{array}$ \\
\hline $\begin{array}{l}\text { 10 Establecimientos de } \\
\text { enseñanza }\end{array}$ & $\begin{array}{l}\text { Dedicados exclusivamente a } \\
\text { programas de formación (enseñanza) }\end{array}$ & $\begin{array}{l}\text { Atraen significativo número de } \\
\text { estudiantes extranjeros. }\end{array}$ \\
\hline $\begin{array}{l}\text { 5 Establecimientos de } \\
\text { gran tamaño }\end{array}$ & $\begin{array}{l}\text { Más dedicados a la investigación } \\
\text { que a los programas de formación } \\
\text { (enseñanza). }\end{array}$ & $\begin{array}{l}\text { Reciben un reducido número } \\
\text { de estudiantes de tiempo } \\
\text { parcial }\end{array}$ \\
\hline $\begin{array}{l}\text { 8 Universidades de } \\
\text { pequeño tamaño }\end{array}$ & $\begin{array}{l}\text { Totalmente volcadas a la } \\
\text { investigación }\end{array}$ & $\begin{array}{l}\text { Reciben estudiantes de tiempo } \\
\text { completo }\end{array}$ \\
\hline $\begin{array}{l}\text { 9 Universidades de gran } \\
\text { tamaño }\end{array}$ & $\begin{array}{l}\text { Aunque asocien actividades de } \\
\text { enseñanza e investigación, prevalece } \\
\text { la oferta de programas de formación } \\
\text { (enseñanza) }\end{array}$ & $\begin{array}{l}\text { Atraen diversas categorías de } \\
\text { estudiantes }\end{array}$ \\
\hline \multicolumn{2}{|l|}{ TOTAL 37 establecimientos de educación superior } \\
\hline
\end{tabular}

Fuente: Datos adaptados de Coaldrake (1999, p. 150).

Puede ser que la poca tradición académica alcanzada por el sistema de educación superior, sumada a la distancia existente entre el país y los centros de investigación internacionales influyan en el perfil del estudiante que atrae: mientras la mayoría de los extranjeros que acoge busca programas de enseñanza (cursos de lengua o preuniversitarios), un reducido grupo escoge universidades australianas para desarrollar investigación; 28\% de los estudiantes extranjeros realizan posgrado, de los cuales un $80 \%$ cursan maestrías y un $8 \%$ doctorados (http://dety.gov.auhghered/research/aiprss.htm consulta realizada el 13/04/2007).

Tomando en cuenta que hace algún tiempo la educación superior en Australia era reconocida como producto de exportación ${ }^{13}$, los números revelan que la expansión del sistema ocurre de forma gradual: en 82 años (1909-1991) fueron creadas 25 universidades públicas y en los últimos 15 años (1992-2007) solo diez nuevos establecimientos fueron fundados (tabla 2), número considerado modesto si se compara con Brasil, que solo en el gobierno de Luiz Inacio da Silva creó 14 nuevas universidades públicas federales.

13 En 2002 era el tercer producto de exportación del sector de servicios y el $14^{\circ}$ en el conjunto de las exportaciones (OCDE, 2002). 
Tabla 2: Establecimientos de educación superior y respectivas fechas de fundación.

\begin{tabular}{|l|c|l|c|}
\hline \multicolumn{1}{|c|}{ Universidad } & $\begin{array}{c}\text { Año de } \\
\text { fundación }\end{array}$ & \multicolumn{1}{|c|}{ Universidad } & $\begin{array}{c}\text { Año de } \\
\text { fundación }\end{array}$ \\
\hline Universidad de Sydney & 1850 & Universidad de Murdoch & 1973 \\
\hline Universidad de Melbourne & 1853 & Universidad Deakim & 1974 \\
\hline Universidad de Adelaide & 1874 & Universidad de Wollongong & 1975 \\
\hline Universidad de Tasmania & 1890 & Universidad Bond & 1987 \\
\hline Universidad de Central Queensland & 1909 & Universidad Tecnológica de Curtin & 1987 \\
\hline Universidad de Australia Occidental & 1911 & Universidad Charles Sturt & 1989 \\
\hline Universidad National de Australia & 1946 & Universidad de Western Sydney & 1989 \\
\hline Universidad de New South Walles & 1948 & Universidad de Northen Territory & 1989 \\
\hline Universidad de Nueva Inglaterra & 1954 & Universidad de Canberra & 1990 \\
\hline Universidad de Monash & 1958 & $\begin{array}{l}\text { Universidad Tecnológica de } \\
\text { Queensland }\end{array}$ & 1990 \\
\hline Universidad James Cook & 1964 & University of South Australia & 1991 \\
\hline Universidad de Newcastle & 1965 & Universidad Católica de Australia & 1991 \\
\hline Universidad Tecnológica de Sydney & 1965 & Universidad Edith Cowan & 1991 \\
\hline $\begin{array}{l}\text { Universidad de Flinders (Sur de } \\
\text { Australia) }\end{array}$ & 1966 & Universidad Victoria & 1991 \\
\hline Universidad de Griffith & 1971 & & \\
\hline
\end{tabular}

Fuente: Datos adaptados de Rossato (1998 pp. 234/235).

Hasta la década del 60, la gestión de las universidades, facultades y cursos era confiada a profesores-investigadores titulares, elegidos entre los más destacados y con experiencia. En los años 1960 y 1970 con el crecimiento de flujo de estudiantes, se pone en práctica un sistema de gestión rotativo entre los profesores más calificados. En las décadas de los ochenta y noventa las universidades se distancian de una identidad más académica y se aproximan a un estilo empresarial.

Esto equivale a decir que ganaron autonomía para organizar actividades de enseñanza e investigación y para administrar recursos humanos y financieros; sus dirigentes dejan de ser elegidos y pasan a ser nombrados según criterios que abarcan competencias más administrativas que académicas (Meck, Wood, 1997, citado en Harman, 2002, p. 62). En tales circunstancias, "no es esencial que un decano o un director sea igualmente investigador [...] es más importante que disponga de una reconocida competencia en fianzas y en gestión" (Harman, 2002, p. 64) ${ }^{14}$. Por lo tanto, no sorprende

14 "N'est pas essentiel qu'un doyen ou un directeur soit également un chercheur [..] il est plus important qu'il dispose de bonnes compétences en matière de finances et de gestion" (Harman, 2002, p. 64). 
que los rectores se identifiquen más con dirigentes de empresas que con representantes de corporaciones académicas.

Es en este contexto, al final de la década de los ochenta, el gobierno laborista admite absoluta ausencia de condiciones para costear el proceso de expansión de la educación superior, en las proporciones requeridas por el proyecto antes mencionado, y defiende la implementación de una política educacional que promueva la diversificación del financiamiento del sistema educativo. En 1987, el ministro del Empleo, Educación y Formación (John Dawkins) declaró que "el gobierno reconocía que a él sólo le sería difícil invertir los recursos capaces de asegurar un significativo incremento de la enseñanza terciaria y proponía diversas soluciones para recolectar fondos con aquellos que se beneficiarán" (citado en Harman, 1999, p. 10) ${ }^{15}$.

En pronunciamiento posterior aclara:

"... deseamos que Australia disponga de una enseñanza de primera línea y de calidad internacional y que sea reconocida como tal. Esperamos una eficiencia y una eficacia creciente en la utilización de los recursos del Estado y animamos a los establecimientos a ampliar y diversificar sus fuentes de recursos financieros de modo que crecientemente se autofinancien, sabiendo que pueden contar con algún recurso público" (Según Coaldrake, 1999, p. 135).

Para esto se ha creado un modelo de costo, de modo que el conjunto de las universidades esté obligado a cobrar aranceles parciales a los estudiantes de pregrado, totales a los de posgrado y mayores a los estudiantes extranjeros (OCDE, 2002, p. 112). Aunque el sistema de educación superior tenga acceso público a esta formación, depende cada vez más de las mensualidades pagadas por los estudiantes nacionales ${ }^{16}$ y extranjeros, ya que los resultados financieros alcanzados con la comercialización de los servicios educacionales

15 "Le gouvernement reconnaissait qu'il lui serait difficile de fournir, à lui seul, les ressources nécessaires pour assurer un élargissement signicatif de l'enseignement supérieur et proposait diverses solutions pour recueillir des fonds auprès de ceux qui en bénéficient" (citado en Harman, 1999, p. 10).

16 El país ofrece una línea de crédito para estudiantes universitarios de origen australiano y el pago del valor correspondiente al préstamo contraído se produce al término del curso (Andruchak, 2006). 
retornan a las instituciones que hacen viables las inversiones en actividades de enseñanza e investigación (McBurnie, 2001, p. 16). Con la adopción del modelo de costo hubo una significativa reducción de la participación directa del Estado en la educación superior y un aumento del financiamiento de los estudiantes o sus respectivas familias. Sobre esto Lynn Meek (2004, p. 1025), aclara:

\begin{abstract}
"si al comienzo de los años 1980 las fuentes no gubernamentales de financiamiento para la educación superior eran insignificantes, hoy día varias universidades, especialmente las más antiguas y bien establecidas, reciben más de la mitad (algunas hasta casi el 75\%) de su ingreso operacional de fuentes no gubernamentales."
\end{abstract}

Este conjunto de determinaciones lleva al autor (2004, p. 1040) a afirmar que en los últimos años el Estado australiano está determinado a disponer de algo sin asumir responsabilidades por el pago de lo que desea, en la medida que "quiera un sistema de educación superior que contribuya al crecimiento y la prosperidad de una sociedad y de una economía basadas en el conocimiento, aunque haciendo, cada vez más, que otros paguen por él". El éxito de la iniciativa queda reflejado en las cifras, conforme a las cuales en el año 2003-2004 el valor de las exportaciones en servicios de educación fue estimado en 7.5 millones de dólares australianos, representando el tercer producto de la cartera de servicios de exportación y el sexto del total de las exportaciones del país (Thorn, citado en Filippetti, 2007, p. 13).

¿Cuál es el impacto ejercido por la reducción del papel del Estado en el financiamiento de la educación superior y por la innegable dependencia de las instituciones vis-a-vis al valor de aranceles pagados por los estudiantes y a la comercialización de servicios educacionales?

Las instituciones de educación superior se hacen más vulnerables porque son subalternas a presiones exógenas, expresadas por las necesidades resultantes del proyecto de desarrollo del país, de las empresas y de los estudiantes-clientes; por la ostentosa evaluación y ranking de performance impuesta a las instituciones y al personal docente y administrativo; la reducción de contratos de tiempo 
completo; presión por la elevación de productividad y competitividad, tanto en el ámbito nacional como internacional. La explicitación de estas cuestiones está registrada en las palabras de Coaldrake (1999, p. 151): "[...]: cada vez más las partes interesadas, externas a la universidad, particularmente los estudiantes, los empleadores y los poderes públicos, presionan a las universidades a asegurar la oferta de un servicio útil, porque cuanto más útil, más rentable será"17.

Teniendo en vista la extensión y profundidad de los cambios impuestos a las universidades australianas, es curioso que representantes de la sociedad y del medio académico (estudiantes, profesores, investigadores y dirigentes) no hayan reaccionado. No obstante, conviene recordar que en Occidente, en general, y en Australia en particular, más de la mitad de las universidades fueron establecidas después de 1945 (tabla 2); en consecuencia, son productos de la iniciativa y de los intereses del Estado. Por esto mismo son instituciones que respetan la política instituida por el gobierno y están condicionalmente al servicio de los intereses nacionales. Son raros los países en los que el poder de influencia ejercido por profesores y estudiantes es resguardado (Charles et al., 2004). Además de eso, cabe recordar que la formación del sistema educacional australiano fue fuertemente influenciada por el pragmatismo que modeló las universidades inglesas y americanas, al punto que, todavía hoy, la presencia de profesores y directivos ingleses en las universidades australianas no es menor (esta cuestión será retomada).

En esta perspectiva, no es de extrañarse que a fines de la década de los noventa (oct. 1997), preocupado por la capacidad de los establecimientos de enseñanza superior para competir mundialmente en mercados educacionales más desregulados y sometidos a las nuevas exigencias de un mercado de trabajo en transformación, Roderick West (profesor y director jubilado de una universidad privada) publica un informe en el que propone la instauración de un ambicioso programa de evaluación del sector de educación superior, la formulación de un plan estratégico que impulse a las instituciones a hacerse más

17 Para Coaldrake (1999, p. 151), “...les parties prenantes extérieures ál'université notamment les étudiants eux-mes, les employeurs et les pouvoirs publics poussent de plus en plus les universités à montrer qu'elles assurent un service utile et, qui plus est, rentable". 
competitivas interna y externamente, y la reestructuración de los programas de financiamiento de la investigación en el país. (Harman, 1999, pp. 15/16).

Curiosamente, muy próximamente, Coaldrake (1999, pp. 138-39) publica un texto en que asocia la competitividad del sistema educacional australiano al valor de los aranceles cobrados. Para el autor, en el ámbito de los cursos de pregrado, los establecimientos usan aranceles inferiores a la media internacional (4.600 libras). Incluso las universidades orientadas a la investigación, justamente aquellas que disponen de mayor presupuesto, cobran aranceles anuales que no pasan las 7.500 libras (valor próximo a la media practicada por las universidades públicas americanas). En términos del autor, "esta situación confirió a Australia una cierta ventaja competitiva en el mercado internacional de estudios"18.

El hecho de que la competitividad del sistema educacional del país esté vinculada a la reducción de costos y no a la notabilidad de los profesores-investigadores o a la calidad de los cursos y de la investigación, suena como algo fuera de lugar. Porque en el ámbito de la competencia internacional la dimensión cualitativa (que corresponde a la concepción estratégica del negocio) y cuantitativa (que expresa la racionalidad de la gestión) son indisociables. La composición del precio está en el ámbito de la dimensión cuantitativa.

¿Cuál sería el espacio conquistado por la producción del conocimiento en el país? Australia presenta actualmente una base científica razonablemente desarrollada. Contribuyó con el 2,88\% de las investigaciones publicadas en el ámbito mundial (Meek, 2004). A diferencia de la mayoría de los estados centrales, mientras el sector empresarial tiene una baja participación en las inversiones en I+D (investigación y desarrollo) (4,9\%, en 2000), el sector público conserva gran participación en esta actividad: casi el 90\%, en igual periodo. El gobierno federal invierte en I+D por medio de diferentes programas y organizaciones, los dos más representativos son la Commonwelth Scientific and Industrial Research Organization (612 millones de dólares

18 Para Coaldrake (1999, pp. 138/39), "cette situation a donné á l'Australie un certain avantage compétitif sur le marché intational des études". 
anuales) y las universidades nacionales (6.652 millones de dólares al año). Meek (2004, p. 1.028) asegura que esto se debe al hecho de que la mayor parte de las grandes multinacionales tienen sus sedes fuera de Australia y a la inexistencia de fundaciones privadas de fomento a la investigación. Esto explicaría el desequilibrio existente entre inversiones realizadas por el país ( $1,53 \%$ del PIB) y la media de inversión de los países de la OCDE (2,25\% del PIB). Pero, en un informe emitido por el gobierno (citado en Coaldrake, 1999, p. 143), las razones que explican la baja participación del sector privado en los programas de investigación supera lo que fue afirmado. Las dificultades identificadas pueden ser agrupadas en cuatro aspectos: a) poca colaboración entre investigadores; b) distancia entre investigadores y usuarios de la investigación (academia e industria, por ejemplo); c) limitada masa crítica debido a la dilución institucional y geográfica de la producción y utilización de la investigación; d) aislamiento de los investigadores respecto de los centros de investigación e innovación mundiales. El último ítem puede ser puesto en duda pues es sabido que desde la emergencia de las primeras universidades, la mayoría de los profesores-investigadores era reclutada en el exterior y que esta práctica todavía está muy presente en los días actuales:

"Persiste una fuerte tendencia de reclutar gran número de profesores titulares y otros profesionales de la enseñanza en el extranjero, tendencia que puede traducirse en una preocupación de mantener una cierta calidad de la enseñanza e investigación y al mismo tiempo de mantener una cierta deferencia en relación a los grandes centros de erudición internacional" (Harman, 2002, p. 67). ${ }^{19}$

Las áreas de conocimiento en que el país detenta particular expertise son medicina, ciencias biológicas y astronomía (Meek, 2004).

19 "Une forte tendance à recruter un grand nombre de professeurs titulaires et autres responsable d'enseignement á l'étranger continue de se manifester, tendance qui peut traduire un souci de maintenir un certain niveau d'enseignement et de recherche en même temps qu'une certaine déférence envers les grands centres d'érudition internationaux" (Harman, 2002, p. 67). En los últimos años, mientras $60 \%$ de los profesores universitarios son originarios del país, $40 \%$ todavía son reclutados entre representantes de las comunidades locales de inmigrantes, Por razones históricas, es posible observar una fuerte presencia de profesores de origen británico (Harman, 2002, p. 67). 
A pesar de esto, la población que busca las universidades australianas para estudiar no considera este aspecto. Observando el calendario escolar 1999/2000, con relación a la distribución de los estudiantes extranjeros por área del conocimiento prevalece la búsqueda por cursos en las áreas de administración y economía (49\%), ciencia (14\%), ciencias humanas y sociales (10\%); ingenierías (9\%); ciencias de la salud (8\%) y el 10\% restante está diluido en diversas áreas (Vuilletet, 2005 p. 16). Los datos de 2006 (OCDE, 2008) refuerzan el panorama antes diseñado: la distribución de los estudiantes internacionales por área de conocimiento ocurría de la siguiente forma: ciencias sociales, comercio y derecho $(52,7 \%)$, ciencias (15\%), ingeniería, producción y construcción (11\%); salud y asistencia social (8,3\%), letras, ciencias humanas y artes $(7,4 \%)$; educación (3.); servicios $(1,6 \%$ ) y agronomía (0.7\%) (OCDE, 2008, p. 395).

\section{El estudiante extranjero en el sistema de educación australiano}

La educación internacional está presente en Australia desde 1904, con la llegada espontánea de los primeros estudiantes internacionales. Hasta 1950, la política adoptada por el Estado consistía en autorizar la entrada de alumnos extranjeros aceptados por algunas universidades del país, que dispusieran de recursos propios para vivir, pagar por el curso realizado y se dedicaran a estudiar a tiempo completo. A partir de 1950, además de asegurar la matrícula a los estudiantes extranjeros que pagan, el gobierno australiano acoge gran número de estudiantes originarios de países asiáticos y de la India, en el contexto de un programa de cooperación (Plan de Colombo) -en que el contingente de estudiantes extranjeros no pasara los diez mil-. Algunos reconocieron esta política como forma de inmigración clandestina y con la intención de inhibirla, a partir de 1979, incluso los estudiantes inscritos en el programa de cooperación, fueron sometidos al pago de aranceles anuales cuyo valor representaba un tercio del costo medio del curso superior realizado (Dobson, 2001, pp. 13/14).

Al inicio de la década de los ochenta fueron formadas dos comisiones con el encargo de investigar la presencia de estudiantes 
internacionales en el sistema de educación superior australiano: mientras la Comisión Goldring se concentró en el estudio de la política volcada hacia los estudiantes extranjeros, la Comisión Jackson profundizó en el estudio del programa de cooperación vigente. En 1984 ambas presentaron informes cuyo contenido reflejaba visiones opuestas de educación: mientras Goldring sustentaba que el Estado debería encarar la educación internacional para que el país promoviera acuerdos de cooperación con regiones pobres, Jackson defendía que la educación debería ser explotada comercialmente y recomendaba la adopción de una política agresiva de atracción de estudiantes y exportación de servicios educacionales. Las ideas defendidas por la Comisión Jackson prevalecieron y fueron traducidas en políticas (Dobson, 2001, p. 14) -hechos que ayudan a justificar por qué la educación en el país pasó a ser encarada como producto de exportación-.

A partir de 1986, las universidades son autorizadas para admitir estudiantes extranjeros que tuvieran los prerrequisitos académicos y fuesen capaces de pagar totalmente el valor de los aranceles fijados por la institución. En esa ocasión, se permite también que los estudiantes extranjeros trabajen hasta veinte horas semanales. Para tener una idea de la rapidez con que el estatus de estudiante becado (étudiant aidé) fue alterado por el de estudiante comercial (étudiant commercial), en 1986 el país tenía aproximadamente 20.000 estudiantes extranjeros en régimen de cooperación y 2.000 estudiantes extranjeros pagadores; 12 años después (1998), el 95\% de los estudiantes extranjeros eran pagadores. En la misma fecha (1986) los estudiantes australianos inscritos en programas de posgrado (troisième cycle) debieron pagar por el curso realizado (Dobson, 2001, 15) -hechos que justifican que la educación en el país sea encarada como producto comercial-.

\section{La importancia de la matrícula de estudiantes extranjeros en la balanza comercial australiana}

Desde el final de la década de los ochenta, los resultados económicos alcanzados por el sector educacional en gran parte se deben a la agresividad de la política de atraer estudiantes y exportar servicios 
educacionales. Así, en estos casi 30 años la iniciativa muestra señales de éxito en lo que toca a los objetivos de carácter financiero. De acuerdo con Phillips et al. (según Meek, 2004, p. 1026), entre 1990 y 2004 la población estudiantil en educación superior se duplicó, no obstante el referido aumento habría sido provocado por el ingreso de estudiantes extranjeros que pagan el total de la mensualidad, sin derecho a financiamiento. Para tener una idea del tamaño del desequilibrio en el crecimiento de la matrícula entre nacionales y extranjeros, de 1995 a 2001 el número de estudiantes australianos que ingresan en la educación terciaria aumentó un 8,6\%, en contrapartida, el número de extranjeros que ingresan aumentó en 146\%. La dependencia que el sistema tiene de la matrícula internacional se amplía cuando los gobernantes reconocen una creciente reducción en el número de estudiantes que terminan la enseñanza media (deuxième clase). Esta cuestión preocupa a la sociedad y al gobierno, tanto es así que en un texto publicado en 2001, Dobson (2001, p. 18) -de la Universidad de Monash-afirma que el país traba el debate no resuelto acerca de la influencia que el cobro de la cuota anual ejerce sobre el ingreso de estudiantes pobres en la universidad.

Consciente de que las divisas inyectadas por el estudiante extranjero $-6,4$ billones de dólares australianos solo en el año 2007-2008 (Access Economics PTY Limited for Australian Council for Private Education and Training)-, el país prácticamente no invierte en la formulación de programas de intercambio internacional que involucren reciprocidad. Prueba de esto, es el desequilibrio existente entre el número de estudiantes que envía a instituciones extranjeras y aquellos que recibe en instituciones australianas, comparativamente respecto a los cinco países que lideran la atracción de académicos internacionales: en 2007, mientras recibía 211.526 estudiantes, enviaba solo 9.986 (tabla 3) (UNESCO, 2009). 
Tabla 3: Número de estudiantes recibidos/enviados por países que lideran la matrícula internacional (educación superior).

\begin{tabular}{|l|c|c|}
\hline PAÍSES & $\begin{array}{c}\text { NÚMERO DE ESTUDIANTES } \\
\text { RECIBIDOS }\end{array}$ & $\begin{array}{c}\text { NÚMERO DE ESTUDIANTES } \\
\text { ENVIADOS }\end{array}$ \\
\hline Estados Unidos & 595.874 & 50.265 \\
\hline Reino Unido & 351.470 & 24.115 \\
\hline Francia & 246.612 & 54.021 \\
\hline Australia & 211.526 & 9.986 \\
\hline Alemania & 206.875 & 77.534 \\
\hline
\end{tabular}

Fuente: Recueil de données mondiales sur l'éducation (UNESCO, 2009).

¿Qué justificaría la adopción de políticas y planes de acción determinados para influir sobre la capacidad del país y así ampliar el mercado de educación superior en el ámbito mundial? ¿Cuál es la relación posible de establecer entre la ampliación del mercado de educación superior en el mundo y la reducción del ingreso de australianos a la educción superior? En la perspectiva neoliberal, el crecimiento y la estabilidad económica están directamente vinculados a la reducción de costos salariales. En consecuencia, la legislación se altera en nombre de la liberalización del mercado de trabajo, aun cuando esto implique reducción de los derechos laborales, no incorporación de los salarios a las ganancias de productividad e incremento del costo de vida. Este conjunto de imposiciones influye directamente sobre la reducción del poder de compra interno y la inevitable dependencia del mercado externo (Santos, 2001, p. 40). Un dato corrobora lo que fue antes afirmado "a pesar del discreto crecimiento de la población estudiantil australiana (8,6\% en seis años), más del 50\% compatibiliza actividades de estudio y trabajo, dando claras señales de que el acceso a la educación superior podría ser más significativo si hubiera una política de financiamiento público más atractiva (Gallagher y McBurnie, 2001).

La matrícula de la población estudiantil de origen extranjero está concentrada en establecimientos de enseñanza y no de investigación. Evidencia que requiere particular atención en tres aspectos: a) tanto en el ámbito de países, organizaciones/instituciones y personas, la investigación permanece como un asunto para pocos en tanto corresponde a la actividad más selectiva, onerosa en recursos y tiempo involucrados, y que presenta resultados en el mediano y largo plazo; 
b) el modelo de pago impuesto a la enseñanza superior australiana no fue extendido para las actividades de investigación, en consecuencia los programas de investigación son en su mayoría financiados con recursos públicos porque el valor de los aranceles anuales es incapaz de cubrir el valor de las inversiones requeridas; c) en el ámbito de las actividades de investigación, el sistema de educación superior australiano todavía no se ha distinguido (mundialmente) en áreas específicas del conocimiento y en el ámbito de las actividades de enseñanza, aún no consigue promover un número significativo de profesores, investigadores y tampoco autores en escala mundial. Entonces, ¿cuáles son las medidas que colaboraron para el éxito comercial de la iniciativa?

Para Vuilletet (2005, p. 16), tres acciones merecen ser destacadas en forma particular: a) creación de un bureau especializado en la divulgación del sistema de educación superior australiano, en el ámbito mundial (International Development Project); b) libertad de las instituciones de educación superior para fijar el valor de los aranceles anuales; c) institucionalización de programas de becas de estudio capaz de facilitar el reclutamiento de estudiantes extranjeros ${ }^{20}$. Mientras tanto, otros aspectos merecen ser destacados en forma especial a pesar de que las cuestiones de naturaleza interna y externa colaboran para el éxito de la industria de la enseñanza superior australiana, dimensiones internas prevalecen justamente por el hecho de depender de la definición de políticas gubernamentales y de planes de acción por parte de las universidades (tabla 4).

20 La Universidad de Monash es un ejemplo de "éxito". Creada en 1958 e internacionalizada al final de los años noventa, amplía la cartera de servicios prestados a los estudiantes extranjeros; recepción en el aeropuerto, colaborar en la localización de alojamiento y en los trámites para los contratos de arriendo de inmuebles, ofrecer un consistente programa de orientación académica y profesional, disponer de oficina de divulgación de oportunidades de trabajo para sus alumnos, etc. Poco más del 30\% de los casi 600.000 estudiantes que atrae son originarios de una centena de países diferentes (sitio de la universidad, consultado en 20/11/006). 
Tabla 4: Aspectos internos-externos que influyen en el atractivo de la educación superior australiana.

\begin{tabular}{|c|c|}
\hline Aspectos internos & Aspectos externos \\
\hline $\begin{array}{l}\text { - Creación de la Agencia Australiana de Calidad en Universidades } \\
\text { (AUQA), responsable por la institución de un sistema de evaluación } \\
\text { (auditoría) comprometido con la fijación de un padrón mundial de } \\
\text { calidad en las universidades del país. }\end{array}$ & $\begin{array}{l}\text { - Existencia de significativo número } \\
\text { de interesados en perfeccionar el } \\
\text { dominio de la lengua inglesa. }\end{array}$ \\
\hline $\begin{array}{l}\text { - Creación del Sistema Australiano de Calificación (AQF) } \\
\text { responsable por la simplificación de los criterios de reconocimiento } \\
\text { de diplomas expedidos en el ámbito internacional. }\end{array}$ & $\begin{array}{l}\text { - Creciente valorización de una } \\
\text { formación superior de carácter } \\
\text { multicultural. }\end{array}$ \\
\hline $\begin{array}{l}\text { - Creación del Servicio de Enseñanza para los Estudiantes } \\
\text { Extranjeros (ESOS) responsable por la ampliación de las } \\
\text { condiciones que favorezcan el estudio y el aprendizaje de los } \\
\text { estudiantes extranjeros en el país. }\end{array}$ & $\begin{array}{l}\text { - Existencia de significativo } \\
\text { número de estudiantes } \\
\text { extranjeros que dispone de } \\
\text { elevado poder adquisitivo. }\end{array}$ \\
\hline $\begin{array}{l}\text { - Valor del dólar australiano, comparativamente al valor del dólar } \\
\text { americano y de las libras esterlinas. }\end{array}$ & $\begin{array}{l}\text { - Abundancia de estudiantes } \\
\text { originarios de países cuyo sistema } \\
\text { de educación superior todavía es } \\
\text { incapaz de atender a la demanda } \\
\text { local. }\end{array}$ \\
\hline $\begin{array}{l}\text { - Valor de los aranceles anuales, comparativamente a las practicadas } \\
\text { en los EUA y en el Reino Unido -países tradicionalmente } \\
\text { receptores de estudiantes y exportadores de productos y servicios } \\
\text { educacionales-. }\end{array}$ & $\begin{array}{l}\text { - Imagen que el país forma entre } \\
\text { creciente número de jóvenes: } \\
\text { cordialidad de las personas, } \\
\text { calidad de vida, seguridad } \\
\text { pública, clima favorable, } \\
\text { diversidad de atracciones para el } \\
\text { tiempo libre. }\end{array}$ \\
\hline - Oferta de cursos de graduación y posgrado en inglés. & $\begin{array}{l}\text { - Existencia de un programa } \\
\text { de incentivo a la migración } \\
\text { calificada (General Skilled } \\
\text { Migration Program). }\end{array}$ \\
\hline \multicolumn{2}{|c|}{\begin{tabular}{l|l} 
- Disponibilidad para ofrecer diversos formatos de programas & \\
en business administration (49\% de la matrícula de estudiantes & \\
extranjeros son en cursos de Administración y Economía). & \\
\end{tabular}} \\
\hline $\begin{array}{l}\text { - Existencia de actividades remuneradas para estudiantes } \\
\text { universitarios (que no excedan } 20 \text { horas semanales), asociada a la } \\
\text { oferta de cursos de tiempo parcial. }\end{array}$ & \\
\hline $\begin{array}{l}\text { - De acuerdo con la nacionalidad hay facilidades de obtención de } \\
\text { visa de estudiante. }\end{array}$ & \\
\hline
\end{tabular}

Fuente: Adaptado de las lecturas realizadas.

A pesar de que la mayoría de los aspectos internos están asociados a medidas administrativas y no académico-pedagógicas, en conjunto ellas colaboran para la ampliación del número de estudiantes extranjeros: en 1988 el país acogió 21.000; en 1994 ellos eran 100.606; en 1998 se elevaron a 147.136; en 1999, 117.485; en 2000-2001, 105.764; en 2001-2002 el número alcanzó 120.987; en 2002-2003 a 179.619, en 2004, 166.954; en 2005 eran 207.264, en 2006, 207.264, y en 2007 la cifra llegó a 211.500 (UNESCO, 2003; 2004; 2005; 2006; 2007; 2008; 2009). Mientras la tasa media de 
crecimiento anual está próxima al 13\%, en los países con tradición en la recepción de estudiantes extranjeros (Estados Unidos, Reino Unido, Alemania y Francia, por ejemplo) la tasa media de crecimiento anual no supera el $6 \%$. Se subraya que estos números revelan parte de la población estudiantil, ya que 35 universidades australianas informaban ofrecer 750 cursos transnacionales en 1999, y la población formada de estudiantes extranjeros estaba dividida de la siguiente forma: 65\% residentes en Australia (en campus); 35\% residentes fuera de Australia (29\% fuera del campus y $6 \%$ en cursos a distancia) (Vuilletet, 2005, p. 73).

Tabla 5: Número de estudiantes extranjeros en Australia (educación superior).

\begin{tabular}{|c|c|}
\hline Año escolar & Número de estudiantes \\
\hline $2000-2001$ & 105.764 \\
\hline $2001-2002$ & 120.987 \\
\hline $2002-2003$ & 179.619 \\
\hline 2004 & 166.954 \\
\hline 2005 & 207.264 \\
\hline 2006 & 207.264 \\
\hline 2007 & 211.526 \\
\hline
\end{tabular}

Fuente: Recueil de données mondiales sur l'éducation (UNESCO, 2003; 2004; 2005; 2006; 2007; 2008; 2009).

Cabe destacar que la permanencia de estudiantes extranjeros en el país representa desembolsos muy superiores al valor correspondiente a los aranceles anuales exigidos por las instituciones. Los estudiantes o las respectivas familias pagan por los costos directos e indirectos implicados en los programas de movilidad estudiantil: gastos relativos al transporte, seguro de salud, alojamiento, alimentación, vestuario, material de apoyo al curso en desarrollo (microcomputador, software, libros, entre otros), así como los costos de oportunidad representados por salarios no ganados por el estudiante durante el tiempo de asistencia a la universidad (Cabrito, 2004, p. 983). Además de esto, las universidades australianas cobran tasas (derechos) en que están incorporados gastos disociados de la actividad pedagógica: uso de biblioteca, multas por atraso de pago, costo de exámenes, estacionamiento, entre otros (Dobson, 2001, p. 18). 
Los estudiantes originarios de países en que el sistema de educación superior, además de subvencionado por el Estado es reconocido mundialmente por la calidad académica, difícilmente migrarían a Australia, motivados por el deseo de ingresar a esta enseñanza. Esto ayuda a entender por qué la población estudiantil extranjera en el país es predominantemente originaria de países localizados en Asia y el Pacífico: considerando un periodo de ocho años, la representatividad de los estudiantes de estas regiones es inconfundible (tabla 6).

Tabla 6: Población estudiantil internacional en Australia: los diez países mejor representados (educación superior).

\begin{tabular}{|l|r|r|r|r|r|r|r|r|}
\hline PAÍSES & \multicolumn{1}{|c|}{1999} & $2000-2001$ & \multicolumn{1}{c|}{2002} & \multicolumn{1}{c|}{2003} & \multicolumn{1}{c|}{2004} & \multicolumn{1}{c|}{2005} & \multicolumn{1}{l|}{2006} & \multicolumn{1}{c|}{2007} \\
\hline CHINA & 4.578 & 5.008 & 17.343 & 23.448 & 28.309 & 40.316 & 40.316 & 50.418 \\
\hline INDIA & 3.697 & 4.578 & 9.539 & 12.384 & 15.742 & 22.039 & 22.039 & 24.523 \\
\hline MALASIA & 16.482 & 12.869 & 17.574 & 19.431 & 16.094 & 18.538 & 18.538 & 17.691 \\
\hline HONG-KONG & 14.705 & 7.546 & 13.471 & 15.118 & 13.165 & 13.525 & 13.525 & 13.464 \\
\hline INDONESIA & 8.976 & 9.934 & 13.658 & 13.260 & 10.184 & 11.302 & 11.302 & 10.536 \\
\hline SINGAPUR & 17.082 & 10.056 & 16.184 & 15.238 & 11.200 & 11.206 & 11.206 & 9.429 \\
\hline REINO UNIDO & 4.690 & 4.430 & 5.968 & 5.924 & 1.652 & 5.412 & 5.412 & 1.687 \\
\hline NUEVA ZELANDA & 4.146 & 4.270 & 5.494 & 4.960 & 4.524 & 5.309 & 5.309 & 2.008 \\
\hline TAILANDIA & 2.609 & 2.693 & 5.023 & 5.666 & 5.449 & 5.014 & 5.014 & 4.884 \\
\hline COREA DEL SUR & 2.117 & 2.361 & 3.935 & 4.265 & 3.915 & 4.889 & 4.889 & 5.430 \\
\hline TOTAL REGIÓN & 79.082 & 63.745 & 108.189 & 119.694 & 110.234 & 137.550 & 137.550 & 140.070 \\
\hline TOTAL GENERAL & 117.485 & 105.764 & 179.919 & 188.160 & 166.954 & 207.264 & 207.264 & 211.526 \\
\hline
\end{tabular}

Fuente: Campus France (2008, p.10); Recueil de données mondiales sur l'éducation (UNESCO, 2006; 2007; 2008; 2009).

Las regiones más subrepresentadas en la matrícula de las instituciones de educación superior australiana son Asia Central (158 en 2004; 212 en 2005 y 2006, respectivamente, y 194 en 2007), Europa Central y Oriental (1.536 en 2004; 2.247 en 2005 y 2006, respectivamente, y 1.524 en 2007), y América Latina y el Caribe (1.911 en 2004; 2.448 en 2005 y 2006, respectivamente, y 2.394 en 2007). No sería exagerado afirmar que el éxito de la industria de la enseñanza en Australia depende de la matrícula de estudiantes originarios de regiones periféricas y semiperiféricas de Asia y Pacífico (163.691), África (6.487) y América Latina y el Caribe (2.394) (UNESCO, 2009). 
La preferencia de los estudiantes asiáticos por cursos superiores de administración y economía puede estar asociada al deseo de iniciarse en las reglas de la economía de mercado y desarrollar mayor familiaridad con las nuevas tecnologías. Regularmente, estos estudiantes retornan a los países de origen y, con el tiempo, se convierten en facilitadores de los intereses económicos provistos por los inversionistas australianos en sus respectivos países. En términos de Vuilletet (2005 p. 16),

"Actualmente, las universidades australianas invierten aproximadamente 250 millones de dólares australianos (150 millones de euros) en promoción en el extranjero, a pesar de que los recursos generados en 2002 hayan sido estimados en 4,2 millones de dólares australianos (2,5 millones de euros), quiere decir, ocupa el tercer lugar en la balanza comercial, contra 0,6 millones australianos hace una década (1988-1989)"21.

De todas maneras, quedan dudas acerca de los resultados educacionales alcanzados por la iniciativa, ya que el proyecto de expansión fue realizado con la privatización del financiamiento de la educación superior y esto repercute sobre la democratización del acceso a la educación superior -consecuencia indeseable cuando el discurso de los gobiernos coinciden sobre la importancia que el país promueva el desarrollo económico por la innovación del sector productivo, por medio del incremento de las exportaciones de $\mathrm{C}+\mathrm{T}$ (Ciencia y Tecnología) y del desarrollo de competencias valoradas por el mercado. Tratando de ayudar a la definición de políticas de educación superior, aunque no profundice en los siete aspectos que recomienda especial atención, Coaldrake (1999, p. 151) advierte a las autoridades del hecho de que "un número muy importante de estudiantes lleguen al final de los estudios insatisfechos con su experiencia universitaria"22.

21 "Aujourd'hui les universités australiennes consacrent environ 250 million de dollars australiens (150 millions d'euros) a leur promotion a l'étranger, alors que le revenu généré en 2002 est estimé a 4,2 milliards de dollars ».

22 "Produire des sources supplémentaires de revenu", "d'améliorer le profil et d'accrôttre la réputation institutionnel” (Davis; Olsen; Bohm citado en McBurnie, 2001, p. 16). 
Los resultados de levantamientos realizados en 1977 y 1997 objetivando, entre otras preocupaciones, conocer el grado de satisfacción de directores, coordinadores y profesores con el trabajo administrativo y docente, apuntan a la reducción en la satisfacción de las tres categorías: tomándose el conjunto de la profesión universitaria poco menos de tres cuartos están insatisfechos con la actividad que realizan, y si tuvieran oportunidad de recomenzar, escogerían otra actividad profesional. Los resultados de levantamientos citados arriba revelan que los profesores se manifiestan más críticos a la agenda neoliberal que la administración universitaria: solo el 34,8\% de los profesores concuerdan que la educación superior debe servir a los intereses de la economía nacional; 91,2\% defienden mayor participación del Estado en el financiamiento de la educación superior; $64,7 \%$ son contrarios al cobro de aranceles anuales a los estudiantes australianos que realizan cursos de pregrado, y sólo 31,3\% son favorables al cobro de aranceles anuales a los estudiantes australianos que realizan curso de posgrado strictu sensu (tabla 7).

Tabla 7: Valores subyacentes al discurso de coordinadores, directores y profesores

\begin{tabular}{|l|c|c|}
\hline Descriptores & $\begin{array}{c}\text { Coord. y } \\
\text { Directores. }\end{array}$ & $\begin{array}{c}\text { Demás } \\
\text { prof. }\end{array}$ \\
\hline $\begin{array}{l}\text { - La educación superior debe servir a los intereses de la economía } \\
\text { nacional. }\end{array}$ & 41,3 & 34,8 \\
\hline - Existe excesivo número de universidades en Australia & 52,3 & 39,2 \\
\hline $\begin{array}{l}\text {-La competencia puede llevar algunas universidades a la falencia o a } \\
\text { procesos de fusión. }\end{array}$ & 67,6 & 57,4 \\
\hline $\begin{array}{l}\text { - Las multinacionales deberían ser autorizadas a ofrecer cursos } \\
\text { universitarios y a expedir diplomas. }\end{array}$ & 5,7 & 11,3 \\
\hline $\begin{array}{l}\text { - La ampliación de la inversión pública es prerrequisito para Australia } \\
\text { mantener la competitividad en sector educacional. }\end{array}$ & 92,4 & 91,2 \\
\hline $\begin{array}{l}\text { - Soy favorable a la implantación de un sistema de crédito que viabilice } \\
\text { la educación superior para quien lo deseare. }\end{array}$ & 14,3 & 17,2 \\
\hline $\begin{array}{l}\text { - La reducción de la calidad de los cursos es resultado del aumento de } \\
\text { inscripciones. }\end{array}$ & 75,2 & 74,6 \\
\hline - Las IES privadas deberían tener derecho a subvenciones del gobierno. & 9,6 & 17,2 \\
\hline $\begin{array}{l}\text { - Estoy contra el cobro de aranceles anuales a los estudiantes } \\
\text { australianos del 1 }{ }^{\circ} \text { y 2 ciclo. }\end{array}$ & 58,1 & 64,7 \\
\hline $\begin{array}{l}\text { - Estoy a favor del cobro de aranceles anuales a los estudiantes } \\
\text { australianos al 3 ciclo. }\end{array}$ & 40,9 & 31,3 \\
\hline
\end{tabular}

Fuente: Harman, Grant. Responsables universitaires ou chefs d'entreprise. Doyens et directeurs dans le système d'enseignement supérieur australien entre 1977 et 1997. Gestion de l'enseignement supérieur. Vol. 14, n. ${ }^{\circ}$ 2, 2002. 
En este contexto, algunos conceptos ganan sentido y razón de ser -capitalismo académico, industria de la enseñanza, turismo cultural, economía del conocimiento, universidad-empresa- cuando las instituciones sobreviven con la multiplicación de unidades de negocio, en una perspectiva claramente empresarial. Al imprimir objetivos comerciales a las actividades educativas, muchas universidades corren el riesgo de desvirtuar el sentido de la enseñanza y de la investigación. Mientras algunas priorizarán la investigación sin autonomía para definir la agenda de investigación, otras se especializarán en actividades de enseñanza de acuerdo a la necesidad determinada por el mercado mundial de estudiantes, en cursos que exigen poca dedicación a los estudios, en áreas comercialmente atractivas y de corto plazo, que traducen más la preferencia de los alumnos-clientes y menos las necesidades de la sociedad. Esta idea está reforzada por los mismos representantes de los establecimientos educacionales australianos. De acuerdo con las respuestas registradas por representantes de universidades, la gran mayoría asegura que las motivaciones que nutren su interés por la educación superior se concentran en la posibilidad de "producir fuentes suplementarias de recursos", "mejorar el perfil y elevar la reputación institucional" (Davis, Olsen; Bohm comentado en McBurnie, 2001, p. 16) ${ }^{23}$.

\section{Consideraciones finales}

En el plano teórico, se cree que la teoría del capitalismo académico, desarrollada por Slaughter y Leslie, contribuye poco al ejercicio de comprensión del caso australiano, ya que el éxito de la industria de la enseñanza en el país se refleja más en el poder de las universidades para atraer estudiantes extranjeros, dispuestos a pagar por los cursos que realizan, que a la capacidad de producir y comercializar conocimiento útil capaz de responder a la demanda del sector productivo $^{24}$. Las lecturas realizadas hasta el momento apuntan a

23 "Produire des sources supplémentaires de revenu", "d'améliorer le profil et d'accroître la réputation institutionnel” (Davis; Olsen; Bohm comentado en McBurnie, 2001, p. 16).

24 "En los términos de Dobson (2001, p. 19), "la proportion actuelle d'étudiants étrangers fournit une partie de ce revenu non-gouvernamental. Les universités sont sans cesse à la recherche de noveaux marches où recruter les étudiants étrangers, car il s'agit sans doute de la source plus lucrative de financement non-gouvernemental". 
que la teoría de la economía-mundo, propuesta por Wallerstein, ofrece recursos interpretativos más consistentes ya que la creación de universidades globales en países semiperiféricos, determinados a explotar la educación como negocio, no es una cuestión de opción. En un país cuya población gira en torno a los veintidós millones de habitantes, la perspectiva económica de la industria de educación superior depende de la existencia de un mercado mundial de educación desregulado porque internamente no hay escala suficiente para soportar los costos involucrados. Cabe recordar que en seis años (1995 a 2001), mientras el número de estudiantes aumentó 8,6\%, el número de estudiantes extranjeros aumentó 146\% (Phillips et al. citado en Meek, 2004, p. 1026).

Tomando en cuenta que tanto China como India (principales proveedores mundiales de estudiantes) no disimulan sus intenciones de invertir el estatus de emisores por captadores de estudiantes. En este intercambio los países asiáticos (principal mercado de la industria australiana) son el blanco más fácil; vistas la proximidad geográfica y la demanda existentes en países como Malasia, HongKong, Indonesia, Singapur, entre otros (tabla 6), la industria de enseñanza australiana tendrá que renovarse para ser competitiva en otros aspectos y permanecer mundialmente atractiva (tabla 8). Actualmente la competitividad de esta industria está asociada al precio de los servicios comercializados. Mientras compitan con países centrales (Estados Unidos, Reino Unido, Alemania, Francia, Japón, por ejemplo), el precio puede ser hasta considerado un diferencial competitivo. Pero cuando pasen a competir con la industria de la educación de países semiperiféricos (China, India, Nueva Zelanda, República de Corea, Malasia, entre otros), esta variable no será más garantía de competitividad, ya que los procesos de contención de costos por la reducción de la masa salarial de profesores y personal administrativo son fácilmente entendidos en estas regiones. 
Tabla 8: Población estudiantil internacional en países de Asia y Pacífico (educación superior).

\begin{tabular}{|l|c|r|r|r|r|r|c|}
\hline PAÍSES & $2000-2001$ & \multicolumn{1}{c|}{2002} & \multicolumn{1}{c|}{2003} & \multicolumn{1}{c|}{2004} & \multicolumn{1}{c|}{2005} & \multicolumn{1}{c|}{2006} & \multicolumn{1}{c|}{2007} \\
\hline AUSTRALIA & 105.764 & 120.987 & 179.619 & 166.954 & 207.264 & 207.264 & 211.526 \\
\hline CHINA & & & & & & 36.386 & 42.138 \\
\hline NUEVA ZELANDA & 8.210 & 11.069 & 17.732 & 26.359 & 40.774 & 40.774 & 33.047 \\
\hline REP. DE COREA & 3.373 & 4.956 & 4.956 & 7.843 & 15.497 & 22.260 & 31.943 \\
\hline MALASIA & 18.892 & 2.989 & 27.731 & 27.731 & 30.407 & 40.029 & 24.404 \\
\hline MACAO & 7.576 & 13.080 & 17.541 & 14.627 & 12.711 & 11.930 & 11.930 \\
\hline TAILANDIA & 2.508 & 4.092 & 4.092 & 4.092 & & & 10.967 \\
\hline INDIA & & 7.791 & 7.738 & 7.738 & 7.589 & 7.589 & s.d. \\
\hline HONG-KONG & 1.882 & 2.355 & 2.355 & 3.270 & 3.817 & 6.274 & 6.274 \\
\hline TOTAL REGIÓN & 34.865 & 33.252 & 64.604 & 77.033 & 98.084 & 153.312 & 151.796 \\
\hline
\end{tabular}

Fuente: Campus France (2008, p. 10); Recueil de données mondiales sur l'éducation (UNESCO, 2006; 2007; 2008; 2009).

La política de educación superior en Australia está comprometida en ampliar condiciones que favorezcan la emergencia y consolidación de universidades globales, o sea, organizaciones que a pesar de actuar en el ámbito de los intereses nacionales están desprovistas de proyectos propios, de carácter prioritariamente educacional, orientados por la y para la sociedad. Sin proyecto propio, fácilmente son sometidas a intereses extraños a la educación y pierden legitimidad en cuanto a institución educacional que está al servicio de la sociedad, porque no se responsabilizan en el plano social y adquieren perfiles esencialmente económicos. Al someterse a intereses demasiado poderosos, ellas se tornan impermeables a los ejercicios que involucran reflexión y crítica propositivas -indispensables para la formación de su identidad mientras sea institución educacional, para procesos de transformación de la sociedad, para la educación formal y política de estudiantes e investigadores (Demo, 2000)-. Sin esto, ellas tienen el mundo como espacio de intervención a favor de los intereses económicos y comerciales que nutren. La internacionalización de la educación vista por este prisma refuerza procesos no disfrazados de colonización posmodernos que, en los términos expresados por Santos (2005, p. 49), corresponde al "colonialismo de tercera generación" que tiene por protagonistas "las colonias del colonialismo de segunda generación". 


\section{Referencias bibliográficas}

Afonso, Almerindo Janela (2003) Estado, globalização e políticas educacionais: elementos para uma agenda de investigação. Revista Brasileira de Educação, n. ${ }^{\circ} 22$, jan/fev/mar/abr.

Andruchak, Cinthia (2006) Só os profissionais pagam. Amanhã, setembro.

Arienti, Wagner Leal; Filomeno, Felipe Amin (2005) Economia política do moderno sistema mundial: as contribuições de Wallerstein, Braudel e Arrighi. Campinas; Anais do X Encontro Nacional de Economia Política.

Associação Internacional de Universidades (2003) "Internacionalização da educação superior: tendências e desenvolvimento desde 1998". Educação Superior: reforma, mudança e internacionalização. Anais. Brasília: UNESCO Brasil.

Becker, Bertha K.; Egler, Claudio A. G. (1993) Brasil - uma nova potencia regional na economia-mundo. Rio de Janeiro: Bertrand do Brasil.

Brouillette, Véronique; Fortin, Nicole (2004) La mondialisation néolibérale et l'enseignement supérieur. Jan (mimeo).

Cabrito, Belmiro Gil (2004) O financiamento do ensino superior em Portugal: entre o Estado e o mercado. Campinas: Educação \& Sociedade, Campinas: Cedes, V. 25, n. ${ }^{\circ} 88$, out.

Campusfrance (2008) Les étudiants internationaux: chiffres clés. Paris: Agence CampusFrance, septembre.

Charle, Christophe et al. (2004) Ensino superior: o momento crítico. Educação E Sociedade. Campinas: Cedes, Vol. 25, n. ${ }^{\circ} 88$, out.

Charle, Christophe; Verger, Jacques (1996) História das universidades. São Paulo: UNESP.

Chauí, Marilena (2002) Escritos sobre universidade. São Paulo: UNESP.

Coaldrake, Peter (1999) L'évolution de l'enseignement supérieur en Australie: perspective internationale. Gestion de l'enseignement supérieur. Vol.11, n. ${ }^{\circ} 1$.

Coggiola, Osvaldo (2001) Universidade e ciência na crise global. São Paulo: Xamã.

Communication from Australia (S/CSS/W/110 de 01/10/2001) mimeo.

Costa, Jurandir Freire (2004) "Perspectivas da juventude na sociedade de mercado" In: Regina Novaes; Paulo Vannichi (orgs.). Juventude e 
sociedade - trabalho, educação, cultura e participação. São Paulo: Editora Fundação Perseu Abramo.

Cortesão, Luiza; Stoer, Stephen R. (2001) Cartografando a transnacionalização do campo educativo: o caso português In: SANTOS, Boaventura Sousa (org.). Globalização - fatalidade ou utopia? $2^{\mathrm{a}}$ ed. Porto: Afrontamento.

Dale, Roger (2004) Globalização e educação: demonstrando a existência de uma 'cultura educacional mundial comum' ou localizando uma agenda globalmente estruturada para a educação? Campinas: Educação \& Sociedade, Vol.25, n. ${ }^{\circ} .87$, mai/ago.

Demo, Pedro (2000) Pesquisa e construção do conhecimento - metodologia científica no caminho de Habermas. Rio de Janeiro: Tempo Brasileiro.

Dias, Marco Antonio Rodrigues (2003) Comercialização no ensino superior: é possível manter a idéia de um bem público? Educação \& Sociedade. Vol. 24 , n. ${ }^{\circ} 84$, set.

(2002) "Educação superior: bem público ou serviço comercial regulamentado pela OMC?" In: Panizzi, Wrana M. (org.) (2001). Universidade - um lugar fora do poder. Porto Alegre: Editora da Ufrgs.

Dobson, Ian. Allez et diversifiez! Grandeur et décadence du financement public de l'enseignement supérieur australien. Gestion de l'enseignement supérieur. Vol.13, n. ${ }^{\circ} 1$.

Fiemeyer, Jean-Claude (2004) Les enseignements supérieures dans le monde, éclatement et effervescence. Paris, Adice-édition.

Filippetti, Aurélie (2007) AVIS présenté au nom de la commission des affaires culturelles, familiales et sociales sur le projet de loi de finances pour 2008 (n.189), n. ${ }^{\circ} 277$.

Harman, Grant (1999) Établir les priorités en matière de financement public pour "apprendre durant toute la vie": recommandations issues de l'examen australien du financement et de la politique de l'enseignement supérieur. Gestion de l'enseignement supérieur. Vol.11, n. ${ }^{\circ} 3$.

(2002) Responsables universitaires ou chefs d'entreprise? Doyens et directeurs dans le système d'enseignement supérieur australien entre 1977 et 1997. Gestion de l'enseignement supérieur. Vol.14, n. ${ }^{\circ} 2$.

Ianni, Octavio (2005) A sociedade global. 12ª ed. Rio de Janeiro: Civilização Brasileira.

McBurnie, Grant (2001) Elever la globalisation au rang de paradigme politique pour l'enseignement supérieur. Enseignement supérieur en Europe, Vol. 26, n. $^{\circ} 1$. 
Meek, V. Lynn (2004) Produção de conhecimento na educação superior australiana: do acadêmico ao comercial. Educação E Sociedade. Vol.25, n. ${ }^{\circ} 88$, out.

Nicolau, José Antônio; Paranhos, Julia (2006) Notas sobre o conceito de inovação. Textos de Economia, Florianópolis, Vol.9, n. ${ }^{\circ} 1$, jan/jun.

OCDE (2008) Regards sur l'éducation 2008 - les indicateurs de l'OCDE. (2002) Analyse des politiques d'éducation. Paris: OCDE.

Pochmann, Marcio (2005) Emprego na globalização - a nova divisão internacional do trabalho e os caminhos que o Brasil escolheu. São Paulo: Boitempo.

Reich, Robert B. (1993) O trabalho das nações: preparando-se para o capitalismo do século XXI. Lisboa: Quetzal Editores.

Rossato, Ricardo (1998) Universidade - nove séculos de história. Passo Fundo: Ediupf.

Santos, Boaventura de Sousa (2005) Universidade no século XXI - para uma reforma democrática e emancipatória da universidade. $2^{a}$ edição. São Paulo: Cortez.

(2001) Os processos de globalização. Santos, Boaventura Sousa (org.). Globalização: fatalidade ou utopia. $2^{a}$ edição. Porto: Afrontamento.

(1997) Pela mão de Alice - o social e o político na pós-modernidade. $4^{a}$ edição. São Paulo: Cortez.

Seixas, Ana M. (2001) "Políticas educativas para o ensino superior: a globalização neoliberal e a emergência de novas formas de regulação estatal" In: Stoer, Stephen R. et al (org.). Transnacionalização da educação: da crise da educação à 'educação' da crise. Porto: Afrontamento.

Slaughter, Sheila; Leslie, Larry (2001) Expanding and elaborating concept of academic capitalism. Organization. London, Vol. 8, n. ${ }^{\circ} 2$, may, p.154-161.

(1997) Academic capitalism: politics, polices and the entrepreneurial university. London: The J. Hopkins University Press.

Stoer, Stephen R. (2001) "Desocultando o vôo das andorinhas: educação intercultural crítica como movimento social" In: Stoer, Stephen R. et al (org.). Transnacionalização da educação: da crise da educação à 'educação' da crise. Porto: Afrontamento.

Teodoro, António (2001) "Organizações internacionais e políticas educativas nacionais: a emergência de novas formas de regulação transnacional, ou uma globalização de baixa intensidade" In: Stoer, Stephen R. et al (org.). 
Transnacionalização da educação: da crise da educação à 'educação' da crise. Porto: Afrontamento.

UNESCO (2003, 2004, 2005, 2006, 2007, 2008, 2009) Recueil des donneés mondiales sur l'éducation: statistiques comparées sur l'éducation dans le monde, Montreal: UNESCO.

Vuilletet, Guillaume (2005) Compaireson internationale des politiques d'accueil des étudiants étrangers: quelles finalités? quels moyens? France: Conseil Économique et Social. oct.

Wallerstein, Immanuel (1976) Semi-peripheral countries and the contemporary world crises. Theory and society. Vol. 3, n. ${ }^{\circ}$ 4. p. 461-483.

Recibido: 14/04/2010

Aceptado: 07/06/2010 